\title{
ПРИМЕНЕНИЕ МЕР БЕЗОПАСНОСТИ КАК ГАРАНТИЯ ПРИНЦИПА ОХРАНЫ ПРАВ И СВОБОД ЧЕЛОВЕКА И ГРАЖДАНИНА В УГОЛОВНОМ СУДОПРОИЗВОДСТВЕ
}

\begin{abstract}
Аннотация: В статье анализируются процессуальные и непроцессуальные меры безопасности, применяемые в предусмотренных законом случаях в целях защиты жизни, здоровья и (или) имущества участников уголовного судопроизводства и иных лиц. Сделан вывод о развитии института мер безопасности: вводятся новые меры безопасности (исключение персональных данных потерпевщего из текста судебного решения при размещении судебных решений в сети Интернет; дифференцированный запрет на распространение в СМИ сведений о несовершеннолетнем потерпевшем и характере причиненных ему страданий, и др.), повышаются требования крешениям о мерах безопасности (составление протокола следственного действия, проведенного с участием потерпевшего, представителя потерпевшего или свидетеля, без указания данных об их личности с 10 января 2014 года требует согласия руководителя следственного органа. Использованы абстрактно-логический, сравнительно-правовой и формально-юридический методы. Проанализированы действующее законодательство, разъяснения Пленума Верховного Суда РФ, правоприменительная практика. Обосновывается вывод о недопустимости применения мер безопасности, не предусмотренных законом (проведение судебного разбирательства в другом регионе Российской Федерации, нахождение одних осужденных отдельно от других в зале судебного заседания и др.), поскольку это может привести к нарушению прав и свобод как самих защищаемых лии, так и других участников уголовного судопроизводства.
\end{abstract}

Ключевые слова: Уголовное судопроизводство, уголовный прочесс, принцип, меры безопасности, гарантии, права и свободы, участник уголовного судопроизводства, суд, следователь, дознаватель.

Abstract: This article analyzes the procedural and non-procedural safety measures implemented in legal cases in order to protect life, health and/or property of the parties involved in criminal procedure and other individuals. A conclusion is made on development of the institution of safety measures: new safety measures are being introduced (exclusion of personal information of the victim from the text of court decisions when they are published online; differentiated prohibition on distribution in mass media of details on victims that are minors, including the nature of their injuries, etc.); the requirements for decisions on safety measures are being increased (filing a report with participation of a victim, their representative or a witness without including their personally-identifying information, since January 10, 2014 requires confirmation from the head of the investigative department). Analysis is conducted on the current legislation, explanation of the Plenum of the Supreme Court of the Russian Federation, and law enforcement practice. The author substantiates a conclusion on the unacceptability of safety measures that are not conducted in accordance with the law (trial in a different region of the Russian Federation, separating the convicts from each other within the court room, etc.), as this can lead to the violation of the right and liberties of both, the defendants, and other participants of criminal proceedings.

Keywords: Criminal procedure, Criminal proceedings, Principle, Safety measures, Guarantees, Rights and liberties, Defendant, Court, Prosecutor, Investigator.

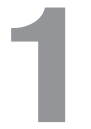

В основе принципа охраны прав и свобод человека и гражданина, действующего как в уголовном судопроизводстве, так и в других сферах общественной деятельности, лежат конституционные положения о том, что человек, его права и свободы является высшей ценностью (ст. 2); права человека,

являясь непосредственно действующими, определяют смысл, содержание и применение законов (ст. 18).

Основное содержание принципа охраны прав и свобод личности заключается в том, что государство обязано признавать, соблюдать и защищать права и свободы человека и гражданина, создавая при этом 
условия для их реализации и механизмы их защиты (ст. 2 и ч. 1 ст. 45 Конституции РФ).

2. Реализация данного принципа в уголовном судопроизводстве обеспечивается рядом правовых гарантий. Например, нарушение следователем права обвиняемого на заявление ходатайств и необоснованный отказ в удовлетворении ходатайств может повлечь возвращение дела прокурору (ст. 237 УПК), вынесение в адрес следователя частного определения или постановления судом (ч. 4 ст. 29 УПК) и др. Так, судом было вынесено частное постановление в адрес руководства УФСКН РФ по Омской области на допущенные следователем нарушения уголовно-процессуального законодательства, которые выразились, в частности, в отказе следователя удовлетворить ходатайство обвиняемого Х. о назначении и производстве фоноскопической экспертизы. Свой отказ следователь мотивировал тем, что «все следственные действия по делу проведены и в любом ходатайстве, поданном обвиняемым, будет отказано», чем нарушил право обвиняемого на защиту ${ }^{1}$.

На сегодняшний день, в условиях активизации преступного мира защита участников уголовного процесса приобрела актуальность не только для России, но и для других государств. Поэтому большое значение для обеспечения принципа охраны прав и свобод личности в уголовном судопроизводстве имеет применение мер безопасности.

За последние годы система уголовного правосудия многих стран разработала различные программы, обеспечивающие оказание защиты, а также моральной и материальной помощи потерпевшим и свидетелям преступлений. Такие программы эффективно применяются в Австрийской Республике, Итальянской Республике, федеративной Республике Германия, Соединенных Штатах Америки и некоторых других государствах 2.

3. В России непроиессуальные меры безопасности предусмотрены Федеральными законами «О полиции» ${ }^{3}$ (п. 11 ч. 1 ст. 2), «Об оперативно-розыскной деятельности» ${ }^{4}$ (п. 5 ст. 7 и п. 6 ст. 14), «О

\footnotetext{
${ }^{1}$ Определение Судебной коллегии по гражданским делам Омского областного суда от 20 июня 2012 года по делу № 33-3672/12 // СПС КонсультантПлюс.

${ }^{2}$ Более подробно см.: Антонович Е.К., Боженок С.Я., Волков А.И. и др. Зарубежный опыт правового регулирования и практика его применения по вопросам защиты участников уголовного судопроизводства / Под общ. ред. В.В. Черникова. - М.: Типография МВД России, 2000.

${ }^{3}$ Федеральный закон от 7 февраля 2011 года № 3-Ф3 «О полиции» // СПС КонсультантПлюс.

${ }^{4}$ Федеральный закон от 12 августа 1995 года № 144-Ф3 «Об оперативно-розыскной деятельности» // СПС КонсультантПлюс.
}

государственной защите судей, должностных лиц правоохранительных и контролирующих органов» ${ }^{5}$, «О государственной защите потерпевших, свидетелей и иных участников уголовного судопроизводства» ${ }^{6}$, Правила применения отдельных мер безопасности в отношении потерпевших, свидетелей и иных участников уголовного судопроизводства ${ }^{7}$, Правила применения меры безопасности в виде переселения защищаемого лица на другое место жительства в отношении потерпевших, свидетелей и иных участников уголовного судопроизводства ${ }^{8}$ и Правила защиты сведений об осуществлении государственной защиты потерпевших, свидетелей и иных участников уголовного судопроизводства 9

4. К мерам безопасности процессуального характера относятся:

1) применение в отношении обвиняемого, подозреваемого меры пресечения, если имеются достаточные основания полагать, что обвиняемый, подозреваемый может угрожать свидетелю или иным участникам уголовного судопроизводства (п. 3 ч. 1 ст. 97 УПК);

2) производство контроля и записи телефонных u иных переговоров потерпевшего, свидетеля или их близких родственников, родственников, близких лиц при наличии угрозы совершения насилия, вымогательства и других преступных действий в отношении этих лиц по их письменному заявлению или на основании судебного решения (ч. 2 ст. 186 УПК).

Отметим, что получение информации о соединениях между абонентами и (или) абонентскими устройствами как следственное действие очень схоже с контролем и записью телефонных и иных переговоров по содержанию, основаниям, порядку и срокам производства. В частности, оба указанных следственных действия могут быть направлены на получение от организации, осуществляющей услуги связи, сведений о будущей (предстоящей) коммуникации тех или иных лиц (ч. 4, 5 ст. 186, ч. 4 ст. 186.1 УПК).

\footnotetext{
${ }^{5}$ Федеральный закон от 20 апреля 1995 года № 45-Ф3 «О государственной защите судей, должностных лиц правоохранительных и контролирующих органов» // СЗ РФ. 1995. № 17. Ст. 1455.

${ }^{6}$ Федеральный закон от 20 августа 2004 г. № 119-Ф3 «О государственной защите потерпевших, свидетелей и иных участников уголовного судопроизводства» // СПС КонсультантПлюс.

7 Утверждены постановлением Правительства РФ от 27 октября 2006 г. № 630 // С3 РФ. 2006. № 45. Ст. 4708.

8 Утверждены постановлением Правительства РФ от 21 сентября 2012 года № 953 // С3 РФ. 2012. № 39. Ст. 5290.

9 Утверждены постановлением Правительства РФ от 3 марта 2007 года № 134 // С3 РФ. 2007. № 11. Ст. 1325.
} 


\section{Право и политика 7 (187) • 2015}

Представляется, что в целях охраны прав и свобод личности в уголовном судопроизводстве получение информации о соединениях между абонентами и (или) абонентскими устройствами (как и контроль и запись телефонных и иных переговоров) может применяться в качестве меры безопасности при наличии угрозы совершения насилия, вымогательства и других преступных действий в отношении потерпевшего, свидетеля или их близких родственников, родственников, близких лиц. Соответствующие дополнения должны найти отражение в ч. 3 ст. 11 и ч. 2.1 ст. 186.1 УПК;

3) производство предъявления лица для опознания в условиях, исключающих визуальное наблюдение опознающего опознаваемым (ч. 8 ст. 193 УПК);

4) составление протокола следственного действия, проведенного с участием потерпевшего, представителя потерпевшего или свидетеля, без указания данных об их личности. Решение об этом выносится следователем с согласия руководителя следственного органа в виде постановления, в котором излагаются причины принятия решения о сохранении в тайне этих данных, указывается псевдоним участника следственного действия и приводится образец его подписи, которые он будет использовать в протоколах следственных действий, произведенных с его участием. Постановление помещается в конверт, который после этого опечатывается, приобщается к уголовному делу и хранится при нем в условиях, исключающих возможность ознакомления с ним иных участников уголовного судопроизводства. В случаях, не терпящих отлагательства, указанное следственное действие может быть произведено на основании постановления следователя о сохранении в тайне данных о личности участника следственного действия без получения согласия руководителя следственного органа. В данном случае постановление следователя передается руководителю следственного органа для проверки его законности и обоснованности незамедлительно при появлении для этого реальной возможности (ч. 9 ст. 166 УПК).

5) закрытое (полностью или частично) судебное разбирательство (п. 4 ч. 2 ст. 241 УПК);

6) допрос свидетеля или потерпевщего в судебном разбирательстве без оглашения подлинных данных об их личности и в условиях, исключающих визуальное наблюдение допрашиваемого лица другими участниками судебного разбирательства (ч. 5 ст. 278 , ч. 1 ст. 277 УПК).

Техническая реализация такого допроса разрабатывается. Оснащение федеральных судов общей юрисдикции комплектами оборудования для допроса потерпевших и свидетелей без возможности их визуального наблюдения является одним из мероприятий федеральной целевой программы «Развитие судебной системы России на 2013 - 2020 годы»

Показания свидетеля, потерпевшего, полученные с использованием указанной процедуры, должны оцениваться наряду с другими доказательствами по делу (ч. 2 ст. 17 УПК). Однако при этом следует учитывать позицию Европейского Суда по правам человека о том, что обвинительный приговор не должен основываться единственно и в решающей степени на анонимных утверждениях ${ }^{11}$.

Недостатком действующего законодательства представляется отсутствие указания на возможность допроса свидетеля или потерпевшего в судебном разбирательстве без оглашения подлинных данных об их личности не только в условиях, исключающих визуальное наблюдение свидетеля (потерпевшего) другими участниками судебного разбирательства, но и в условиях, исключающих возможность опознания свидетеля или потерпевшего другими участниками судебного разбирательства по голосу: если допрашиваемое лицо будет опознано кем-либо из находящихся в зале судебного заседания по голосу, это сделает примененную мену безопасности иллюзорной и неэффективной. Представляется, что ч. 5 ст. 278 и ч. 1 ст. 277 УПК должны быть дополнены соответствующим положением;

7) применение указанных выше мер безопасности по отношению к подозреваемому или обвиняемому, с которым заключено досудебное соглашение о сотрудничестве (ч. 3 ст. 317.4, ст. 317.9 УПК, п. 10 Постановления Пленума Верховного Суда РФ от 28 июня 2012 года № 16 «О практике применения судами особого порядка судебного разбирательства уголовных дел при заключении досудебного соглашения о сотрудничестве» ${ }^{12}$ ). Это обусловлено тем, что в такой подозреваемый, обвиняемый становится своеобразным свидетелем по делу, поскольку он содействует следствию в раскрытии и расследовании преступления, изобличении и уголовном преследовании других соучастников преступления,

\footnotetext{
${ }^{10}$ Утв. постановлением Правительства РФ от 27 декабря 2012 года № 1406 // С3 РФ. 2013. № 1. Ст. 13.

${ }^{11}$ См.: Постановления Европейского суда по правам человека от 26 марта 1996 года по делу Доорсон против Нидерландов (Doorson v. Netherlands). § 76. Reports 1996-II; от 23 апреля 1997 года по делу Ван Мехелен и другие против Нидерландов (Van Mechelen and Others v. Netherlands). § 55. Reports 1997-III. ${ }^{12}$ БВС РФ. 2012. № 9.
} 
розыске имущества, добытого в результате преступления (ч. 2 ст. 317.1 УПК).

В дополнении к мерам, указанным в ч. 3 ст. 11 УПК, в случае возникновения угрозы безопасности подозреваемого или обвиняемого, с которым заключено досудебное соглашение о сотрудничестве, его близких родственников, родственников и близких лиц следователь выносит постановление о хранении в опечатанном конверте процессуальных актов, связанных с заключением досудебного соглашения о сотрудничестве (ходатайства о заключении досудебного соглашения о сотрудничестве, постановления следователя о возбуждении перед прокурором ходатайства о заключении с подозреваемым или обвиняемым досудебного соглашения о сотрудничестве, постановления прокурора об удовлетворении ходатайства о заключении досудебного соглашения о сотрудничестве, досудебного соглашения о сотрудничестве) (ч. 3 ст. 317.4 УПК);

8) исключение персональных данных потерпевшего из текста судебного решения при размещении судебных решений в сети Интернет (п. 17 Постановления Пленума Верховного Суда РФ «О практике применения судами норм, регламентирующих участие потерпевшего в уголовном судопроизводстве» ${ }^{13}$;

9) дифференцированный запрет на распространение в СМИ сведений о несовершеннолетнем потерпевшем и характере причиненных ему страданий (ч. 6 ст. 4, ч. 4 и 5 ст. 41 Закона РФ «О средствах массовой информации» $\left.{ }^{14}\right)$.

Как видим, институт процессуальных мер безопасности развивается: перечень мер расширяется (три последние меры безопасности появились лишь в последние годы), повышаются требования к решениям о мерах безопасности (составление протокола следственного действия, проведенного с участием потерпевшего, представителя потерпевшего или свидетеля, без указания данных об их личности с 10 января 2014 года требует согласия руководителя следственного органа ${ }^{15}$ ).

5. Решение о применении мер безопасности должно быть законным, обоснованным, мотивированным (ч. 4 ст. 7 УПК).

\footnotetext{
13 Постановление Пленума Верховного Суда РФ от 29 июня 2010 года № 17 «О практике применения судами норм, регламентирующих участие потерпевшего в уголовном судопроизводстве» // БВС РФ. 2010. № 9.

14 Закон Российской Федерации от 27 декабря 1991 года № 2124-1 «О средствах массовой информации» // СПС КонсультантПлюс.

${ }^{15}$ Федеральный закон от 28 декабря 2013 года № 432-Ф3 «О внесении изменений в отдельные законодательные акты Российской Федерации в целях совершенствования прав потерпевших в уголовном судопроизводстве // СПС КонсультантПлюс.
}

В частности, в постановлении, определении о применении мер безопасности должны быть указаны конкретные основания для принятия такого решения. Невыполнение этого требования влечет признание полученных доказательств (например, показаний засекреченного свидетеля) недопустимыми.

Необоснованным является решение, постановленное на основании одного лишь заявления лица о том, что его допрос в условиях визуального наблюдения может повлечь для него негативные последствия (возникновение угрозы для жизни, здоровья, уничтожения либо повреждения личного имущества) ${ }^{16}$.

Напротив, применение мер безопасности к трем свидетелям по уголовному делу признано законным и обоснованным, поскольку М., Ч-в, К. и Ч-н обвинялись в совершении преступлений в составе организованной группой, часть членов этой организованной группы находилась на свободе, следовательно, у свидетелей имелись реальные основания опасаться за свою жизнь и здоровье ${ }^{17}$.

6. Предель применения мер безопасности. Хотя меры безопасности направлены на защиту жизни, здоровья и (или) имущества участников уголовного судопроизводства и иных лиц, их применение сопряжено с ограничением других прав и свобод участников. Так, засекречивание данных о свидетеле ограничивает возможности стороны защиты доказать, что он (или она) был предвзят, враждебен или неправдив (то есть ограничивает право подозреваемого, обвиняемого на защиту). Поэтому перечень мер безопасности, предусмотренных УПК РФ, имеет исчерпьвающий характер.

Расширительное толкование ч. 3 ст. 11 УПК не допускается, поскольку может привести к нарушению прав и свобод как других участников уголовного судопроизводства, так и самих защищаемых лиц.

Например, не основано на законе удовлетворение судом ходатайства совершеннолетней потерпевшей о допросе ее в отсутствие подсудимого лишь на том основании, что она, будучи беременной, не желает встречаться с подсудимым и отказывается находиться вместе с ним в зале судебного заседания. В условиях отсутствия данных о наличии какой-либо угрозы со стороны не нарушавшего порядок в судебном заседании обвиняемого у суда не было оснований применять к потерпевшей меру

\footnotetext{
${ }^{16}$ Кассационное определение Судебной коллегии по уголовным делам Верховного Суда РФ от 7 августа 2006 года по делу № 91005-8 // СПС КонсультантПлюс.

${ }^{17}$ Кассационное определение Судебной коллегии по уголовным делам Верховного Суда РФ от 14 июня 2011 года № 4-О11-99СП // СПС КонсультантПлюс.
} 


\section{Право и политика 7 (187) • 2015}

безопасности, тем более, не предусмотренную законом. Принятые судом меры к защите потерпевшей привели к необоснованному ограничению прав подсудимого - он не был ознакомлен с показаниями, которые дала против него потерпевшая в судебном заседании, ее показания, данные ранее, были оглашены в его отсутствие, само право задать потерпевшей вопросы реализовано не было, т.е. его право на защиту было ограничено в такой степени, которая несовместима с требованиями УПК и гарантиями, предусмотренными п. 3 (d) ст. 6 Конвенции о защите прав человека и основных свобод ${ }^{18}$.

Неправомерно применение и такой не предусмотренной законом меры безопасности как проведение судебного разбирательства в другом регионе Российской Федерации, поскольку это нарушает положение, закрепленное в ч. 1 ст. 47 Конституции РФ о том, что никто не может быть лишен права на рассмотрение его дела в том суде и тем судьей, к подсудности которых оно отнесено законом ${ }^{19}$.
Небесспорно применение в качестве меры безопасности нахождение одних осужденных отдельно от других в зале судебного заседания. Подсудимые Б. и Р., обвинявшиеся в участии в банде, в целях их безопасности находились в зале судебного заседания отдельно от подсудимого Л., обвинявшегося в том, что он организовал и возглавил указанную банду. Указанное обстоятельство было признано правомерным, поскольку председательствующий обратил внимание присяжных заседателей на то, что они не должны учитывать это при принятии решения. Однако сама по себе такая обстановка судебного заседания могла вызвать у присяжных заседателей предвзятое, негативное мнение о подсудимом Л., на что ссылались участники со стороны защиты в кассационной жалобе ${ }^{20}$.

На основании изложенного представляется необходимым дополнить ч. 3 ст. 11 УПК положением о запрете применения мер безопасности, не предусмотренных законом.

\section{Библиография:}

1. Жигульских А.Н.. Прокурор в гражданском процессе: позиция Европейского Суда по правам человека // Административное и муниципальное право. - 2012. - № 7. - С. 104-107.

2. Селедникова О.Н.. Некоторые проблемы возмещения имущественного вреда, причиненного преступлением, на стадии предварительного расследования // Административное и муниципальное право. - 2012. - № 8. - С. 104-107.

3. Бекетов М.Ю., Саморока В.А.. Оценка реальности угроз поступающих в адрес участника уголовного судопроизводства при решении вопроса о применении мер безопасности // Полицейская деятельность. - 2012. - № 4. - С. 104-107.

4. М.Н. Склизков. Теоретические и методологические основы исследования сущности судебного решения как юридического факта в гражданском праве // Право и политика. - 2012. - № 11. - С. 104-107.

5. Т.Р. Устов. Следственные действия: характерные признаки и особенности обеспечения прав участников при производстве в стадии возбуждения уголовного дела // Право и политика. - 2012. - № 12. - С. 104-107.

6. Глушков А.И.. Роль прокурора в обеспечении реализации принципа состязательности сторон на досудебных стадиях уголовного процесса // Административное и муниципальное право. - 2013. - № 5. - С. 104-107. DOI: 10.7256/19992807.2013.05.14

7. Нафикова Г.А.. Правозащитный аспект механизма реализации принципа охраны прав и свобод человека и гражданина // Политика и Общество. - 2013. - № 7. - С. 104-107. DOI: 10.7256/1812-8696.2013.7.5001

8. Соколов Т.В.. Взаимосвязь конституционного и уголовного судопроизводств: современное состояние // Право и политика. - 2013. - № 10. - С. 104-107. DOI: 10.7256/1811-9018.2013.10.9496

9. Шевчук П.П.. Актуализация принципов исполнительного производства // Административное и муниципальное право. - 2013. - № 10. - C. 104-107. DOI: 10.7256/1999-2807.2013.10.9743

10. Антонович Е.К., Боженок С.Я., Волков А.И. и др. Зарубежный опыт правового регулирования и практика его применения по вопросам защиты участников уголовного судопроизводства / Под общ. ред. В.В. Черникова. - М.: Типография МВД России, 2000.

11. Бекетов М.Ю., Саморока В.А. Оценка реальности угроз поступающих в адрес участника уголовного судопроизводства при решении вопроса о применении мер безопасности // Полицейская деятельность. - 2012. - 4. - С. 32-37.

12. С. П. Щерба Проблемы нормативного определения сущности и содержания прав и свобод человека и гражданина в уголовном процессе России // Союз криминалистов и криминологов. - 2013. - 2. - С. 150-153.

\footnotetext{
${ }^{18}$ Определение Судебной коллегии по уголовным делам Пермского краевого суда Пермского краевого суда от 28 октября 2010 года по делу № 22-7624 // СПС КонсультантПлюс.

19 Определение Конституционного Суда РФ от 17 декабря 2009 года № 1675-О-О об отказе в принятии к рассмотрению жалобы гражданина Барсукова Владимира Сергеевича на нарушение его конституционных прав частью третьей статьи 11,
}

частью второй статьи 131, статьей 232 и частью пятой статьи 355 Уголовно-процессуального кодекса Российской Федерации // СПС КонсультантПлюс.

${ }^{20}$ Определение Судебной коллегии по уголовным делам Верховного Суда РФ от 7 июля 2006 года № 12-о06-5сп // СПС КонсультантПлюс. 
13. Бекетов М.Ю., Саморока В.А. Оценка реальности угроз поступающих в адрес участника уголовного судопроизводства при решении вопроса о применении мер безопасности // Полицейская деятельность. - 2012. - 4. - С. 32 - 37.

14. Адмиралова И.А., Кареева-Попелковская К.А. Меры административного пресечения и механизм их реализации полицией в целях обеспечения прав и свобод граждан // Административное и муниципальное право. - 2014. - 4. - С. 351 - 359. DOI: 10.7256/1999-2807.2014.4.11434.

15. Киричёк Е.В. Взаимодействие полиции с общественными объединениями и иными институтами гражданского общества в условиях реализации принципа соблюдения и уважения прав и свобод человека и гражданина в Российской Федерации // Административное и муниципальное право. - 2013. - 12. - C. 1139 - 1147. DOI: 10.7256/1999-2807.2013.12.10198.

16. П. П. Ушаков Становление и развитие прав человека в России. // Политика и Общество. - 2011. - 11. - С. 143 - 152.

17. Терехов А.Ю. К вопросу об основаниях выбора способа собирания доказательств в ходе досудебного производства по уголовному делу // NB: Российское полицейское право. - 2013. - 2. - С. 62 - 76. DOI: 10.7256/2306-4218.2013.2.802. URL: http://www.e-notabene.ru/pm/article_802.html

18. Бекетов М.Ю., Саморока В.А. Оценка реальности угроз поступающих в адрес участника уголовного судопроизводства при решении вопроса о применении мер безопасности // Полицейская деятельность. - 2012. - 4. - С. 32 - 37.

19. Адмиралова И.А., Кареева-Попелковская К.А. Меры административного пресечения и механизм их реализации полицией в целях обеспечения прав и свобод граждан // Административное и муниципальное право. - 2014. - 4. - С. 351 - 359. DOI: 10.7256/1999-2807.2014.4.11434.

20. Киричёк Е.В. Взаимодействие полиции с общественными объединениями и иными институтами гражданского общества в условиях реализации принципа соблюдения и уважения прав и свобод человека и гражданина в Российской Федерации // Административное и муниципальное право. - 2013. - 12. - C. 1139 - 1147. DOI: 10.7256/1999-2807.2013.12.10198.

21. П. П. Ушаков Становление и развитие прав человека в России. // Политика и Общество. - 2011. - 11. - С. 143 - 152.

22. Терехов А.Ю. К вопросу об основаниях выбора способа собирания доказательств в ходе досудебного производства по уголовному делу // NB: Российское полицейское право. - 2013. - 2. - С. 62 - 76. DOI: 10.7256/2306-4218.2013.2.802. URL: http://www.e-notabene.ru/pm/article_802.html

\section{References (transliterated):}

1. Zhigul'skikh A.N.. Prokuror v grazhdanskom protsesse: pozitsiya Evropeiskogo Suda po pravam cheloveka // Administrativnoe i munitsipal'noe pravo. - 2012. - № 7. - S. 104-107.

2. Selednikova O.N.. Nekotorye problemy vozmeshcheniya imushchestvennogo vreda, prichinennogo prestupleniem, na stadii predvaritel'nogo rassledovaniya // Administrativnoe i munitsipal'noe pravo. - 2012. - № 8. - S. 104-107.

3. Beketov M.Yu., Samoroka V.A.. Otsenka real'nosti ugroz postupayushchikh v adres uchastnika ugolovnogo sudoproizvodstva pri reshenii voprosa o primenenii mer bezopasnosti // Politseiskaya deyatel'nost'. - 2012. - № 4. - S. 104-107.

4. M.N. Sklizkov. Teoreticheskie i metodologicheskie osnovy issledovaniya sushchnosti sudebnogo resheniya kak yuridicheskogo fakta v grazhdanskom prave // Pravo i politika. - 2012. - № 11. - S. 104-107.

5. T.R. Ustov. Sledstvennye deistviya: kharakternye priznaki i osobennosti obespecheniya prav uchastnikov pri proizvodstve v stadii vozbuzhdeniya ugolovnogo dela // Pravo i politika. - 2012. - № 12. - S. 104-107.

6. Glushkov A.I.. Rol' prokurora v obespechenii realizatsii printsipa sostyazatel'nosti storon na dosudebnykh stadiyakh ugolovnogo protsessa // Administrativnoe i munitsipal'noe pravo. - 2013. - № 5. - S. 104-107. DOI: 10.7256/1999-2807.2013.05.14

7. Nafikova G.A.. Pravozashchitnyi aspekt mekhanizma realizatsii printsipa okhrany prav i svobod cheloveka i grazhdanina // Politika i Obshchestvo. - 2013. - № 7. - S. 104-107. DOI: 10.7256/1812-8696.2013.7.5001

8. Sokolov T.V.. Vzaimosvyaz' konstitutsionnogo i ugolovnogo sudoproizvodstv: sovremennoe sostoyanie // Pravo i politika. - 2013. - № 10. - S. 104-107. DOI: 10.7256/1811-9018.2013.10.9496

9. Shevchuk P.P.. Aktualizatsiya printsipov ispolnitel'nogo proizvodstva // Administrativnoe i munitsipal'noe pravo. - 2013. - № 10. - S. 104-107. DOI: 10.7256/1999-2807.2013.10.9743

10. Antonovich E.K., Bozhenok S.Ya., Volkov A.I. i dr. Zarubezhnyi opyt pravovogo regulirovaniya i praktika ego primeneniya po voprosam zashchity uchastnikov ugolovnogo sudoproizvodstva / Pod obshch. red. V.V. Chernikova. - M.: Tipografiya MVD Rossii, 2000.

11. Beketov M.Yu., Samoroka V.A. Otsenka real'nosti ugroz postupayushchikh v adres uchastnika ugolovnogo sudoproizvodstva pri reshenii voprosa o primenenii mer bezopasnosti // Politseiskaya deyatel'nost'. - 2012 . - 4. - C. 32-37.

12. S. P. Shcherba Problemy normativnogo opredeleniya sushchnosti i soderzhaniya prav i svobod cheloveka i grazhdanina v ugolovnom protsesse Rossii // Soyuz kriminalistov i kriminologov. - 2013. - 2. - C. 150-153.

13. Beketov M.Yu., Samoroka V.A. Otsenka real'nosti ugroz postupayushchikh v adres uchastnika ugolovnogo sudoproizvodstva pri reshenii voprosa o primenenii mer bezopasnosti // Politseiskaya deyatel'nost'. - 2012. - 4. - C. 32 - 37.

14. Admiralova I.A., Kareeva-Popelkovskaya K.A. Mery administrativnogo presecheniya i mekhanizm ikh realizatsii politsiei v tselyakh obespecheniya prav i svobod grazhdan // Administrativnoe i munitsipal'noe pravo. - 2014. - 4. - C. 351 - 359. DOI: 10.7256/1999-2807.2014.4.11434.

15. Kirichek E.V. Vzaimodeistvie politsii s obshchestvennymi ob"edineniyami i inymi institutami grazhdanskogo obshchestva v usloviyakh realizatsii printsipa soblyudeniya i uvazheniya prav i svobod cheloveka i grazhdanina v Rossiiskoi Federatsii // Administrativnoe i munitsipal'noe pravo. - 2013. - 12. - C. 1139 - 1147. DOI: 10.7256/1999-2807.2013.12.10198. 
DOI: 10.7256/1811-9018.2015.7.12806

При цитировании этой статьи сноска на доі обязательна

\section{Право и политика $7(187) \cdot 2015$}

16. P. P. Ushakov Stanovlenie i razvitie prav cheloveka v Rossii. // Politika i Obshchestvo. - 2011. - 11. - C. 143 - 152.

17. Terekhov A.Yu. K voprosu ob osnovaniyakh vybora sposoba sobiraniya dokazatel'stv v khode dosudebnogo proizvodstva po ugolovnomu delu // NB: Rossiiskoe politseiskoe pravo. - 2013. -2. - C. 62 - 76. DOI: 10.7256/2306-4218.2013.2.802. URL: http:// www.e-notabene.ru/pm/article_802.html

18. Beketov M.Yu., Samoroka V.A. Otsenka real'nosti ugroz postupayushchikh v adres uchastnika ugolovnogo sudoproizvodstva pri reshenii voprosa o primenenii mer bezopasnosti // Politseiskaya deyatel'nost'. - 2012. - 4. - C. 32 - 37.

19. Admiralova I.A., Kareeva-Popelkovskaya K.A. Mery administrativnogo presecheniya i mekhanizm ikh realizatsii politsiei v tselyakh obespecheniya prav i svobod grazhdan // Administrativnoe i munitsipal'noe pravo. - 2014. - 4. - C. 351 - 359. DOI: 10.7256/1999-2807.2014.4.11434.

20. Kirichek E.V. Vzaimodeistvie politsii s obshchestvennymi ob"edineniyami i inymi institutami grazhdanskogo obshchestva v usloviyakh realizatsii printsipa soblyudeniya i uvazheniya prav i svobod cheloveka i grazhdanina v Rossiiskoi Federatsii // Administrativnoe i munitsipal'noe pravo. - 2013. - 12. - C. 1139 - 1147. DOI: 10.7256/1999-2807.2013.12.10198.

21. P. P. Ushakov Stanovlenie i razvitie prav cheloveka v Rossii. // Politika i Obshchestvo. - 2011. - 11. - C. 143 - 152.

22. Terekhov A.Yu. K voprosu ob osnovaniyakh vybora sposoba sobiraniya dokazatel'stv v khode dosudebnogo proizvodstva po ugolovnomu delu // NB: Rossiiskoe politseiskoe pravo. - 2013. - 2. - C. 62 - 76. DOI: 10.7256/2306-4218.2013.2.802. URL: http://www.e-notabene.ru/pm/article_802.html 